\title{
Computed tomographic images reflect the biologic behavior of small lung adenocarcinoma: They correlate with cell proliferation, microvascularization, cell adhesion, degradation of extracellular matrix, and K-ras mutation
}

\author{
Boming Dong, MD, ${ }^{a}$ Masami Sato, MD, a,b Akira Sakurada, MD, ${ }^{a}$ Motoyasu Sagawa, MD, a,c Chiaki Endo, MD, \\ Shulin Wu, MD, ${ }^{a}$ Sumitaka Yamanaka, MD, ${ }^{a}$ Akira Horii, MD, ${ }^{d}$ and Takashi Kondo, MDa
}

From the Department of Thoracic Surgery, a Institute of Development, Aging and Cancer, Tohoku University School of Medicine, Sendai, Japan; the Department of Thoracic Surgery, ${ }^{\mathrm{b}}$ Miyagi Cancer Center, Natori, Japan; the Department of Thoracic Surgery, ${ }^{c}$ Kanazawa Medical University, Kanazawa, Japan; and the Department of Molecular Pathology, ${ }^{\mathrm{d}}$ Tohoku University, Sendai, Japan.

This work was supported in part by the Grant-in-Aid from the Ministry of Education, Culture, Sports, Science, and Technology of Japan.

Received for publication March 1, 2005; revisions received April 29, 2005; accepted for publication May 16, 2005

Address for reprints: Masami Sato, MD, Department of Thoracic Surgery, Miyagi Cancer Center, 47-1, Medeshima-Shiote-aza-Nodayama, Natori, 981-1293, Miyagi, Japan (Email: m-sato@mcc.pref.miyagi.jp).

J Thorac Cardiovasc Surg 2005;130:733-9

$0022-5223 / \$ 30.00$

Copyright (c) 2005 by The American Association for Thoracic Surgery

doi:10.1016/j.jtcvs.2005.05.013
Background: We previously reported that the computed tomographic $\mathrm{M} / \mathrm{L}$ ratio (area of the tumor in the mediastinal computed tomographic image/area of the tumor in the lung computed tomographic image) of small peripheral lung adenocarcinoma is correlated with patient prognosis.

Methods: Immunostaining for p53, bcl-2, Ki-67, vascular endothelial growth factor, CD34, matrix metalloproteinase 2, matrix metalloproteinase 9, tissue inhibitor of matrix metalloproteinase 2, and mutation of K-ras was assessed in 131 surgically resected, primary peripheral lung adenocarcinomas of $30 \mathrm{~mm}$ or less in maximum diameter to clarify the relationship between computed tomographic findings and biologic activities.

Results: The numbers of patients with high labeling indexes of Ki-67 and high expression of vascular endothelial growth factor, CD34, matrix metalloproteinase 2, and matrix metalloproteinase 9 in the solid-type group (computed tomographic M/L ratio $\geq 50 \%$ ) were significantly higher than those in the faint density-type group (computed tomographic $\mathrm{M} / \mathrm{L}$ ratio $<50 \% ; P=.04$ for $\mathrm{Ki}-67, P=.03$ for vascular endothelial growth factor, $P=.0009$ for CD34, $P=.001$ for matrix metalloproteinase 2 , and $P=.00001$ for matrix metalloproteinase 9 ). The number of patients with high levels of CD44v6 or tissue inhibitor of matrix metalloproteinase 2 staining in the faint density-type group was significantly higher than that in the solid-type group $(P=.02$ for CD44v6 and $P=.01$ for tissue inhibitor of matrix metalloproteinase 2). Independent variables capable of predicting computed tomographic $\mathrm{M} / \mathrm{L}$ ratio included CD34, matrix metalloproteinase 2, matrix metalloproteinase 9, and tissue inhibitor of matrix metalloproteinase $2(P=.0093, P=.0003, P=.0027$, and $P=.01$, respectively; binary logistic regression analysis).

Conclusions: Our results suggest that the computed tomographic image of small lung adenocarcinoma is correlated with biologic activities and thus provides possible prognostic information.

$\mathrm{R}$ ecently, the number of patients with small peripheral lung cancer detected by means of computed tomographic (CT) scanning has been increasing. Despite the small size of these tumors, some of these patients die of cancer recurrence. Several factors, including lymph node metastasis, histologic subtype, size of the central fibrosis, and bronchioloalveolar carcinoma (BAC) component, have been proved to be of prognostic importance, but few such factors can be evaluated preoperatively. ${ }^{1-4}$ In our previous report we reviewed the CT images of 143 patients with primary peripheral lung adenocarcinoma of $30 \mathrm{~mm}$ or less in maximum diameter and classified the patients according to the CT M/L ratio (area 
of tumor in the mediastinal CT image/area of tumor in the lung CT image) into a faint density-type group (CT M/L ratio $<50 \%)$ and a solid-type group $(\mathrm{CT} \mathrm{M} / \mathrm{L}$ ratio $\geq 50 \%){ }^{5}$ As a result, we found that the 5-year survival of patients with faint density-type CT images was significantly better than that of patients with solid-type CT images. Even when the analyses were limited to the patients without nodal involvement, there was also a significant difference between the 2 groups. Multivariate analysis revealed the effect on prognostic influence of the $\mathrm{CT} \mathrm{M} / \mathrm{L}$ ratio on survival to be the second highest after that of the $\mathrm{N}$ factor. ${ }^{5}$ Thus preoperative classification of patients according to the CT M/L ratio is a simple but powerful predictor of prognosis for patients with small-sized lung adenocarcinoma. Adjuvant treatments, such as chemotherapy and molecular target therapy, are probably necessary for patients with sold-type CT images. Thus it is important to know the mechanism by which CT M/L ratio can be used to predict the prognosis for patients with small-sized lung adenocarcinoma.

The CT M/L ratio might be affected by the pathologic structure of the tumor. BAC components show low cellular density because the tumor cells often extend by mimicking normal alveolar structure. In contrast, fibroblastic proliferation, formation of a central scar, and neovascularization might all contribute to an increase in the value of the CT $\mathrm{M} / \mathrm{L}$ ratio. None of these factors, however, seems to uniquely predominate in this CT-pathology-survival correlation. On the other hand, p53, Ki-67, bcl-2, CD44v6, vascular endothelial growth factor (VEGF), matrix metalloproteinase 2 (MMP-2), MMP-9, tissue inhibitor of MMP-2 (TIMP-2), and K-ras, which were reported to be prognostic factors of small adenocarcinoma, have some influence on histologic structure by affecting cell proliferation, apoptosis, microvascularization, cell adhesion, and the degradation of the extracellular matrix. ${ }^{6-10}$ The purpose of this study was to identify the biologic factors that either correlated with the CT M/L ratio or predict the prognosis of small lung adenocarcinoma, so as to clarify the mechanism of the CT-pathology-survival correlation.

\section{Materials and Methods}

\section{Patients, CT Image Analyses, and Tissue Specimen}

In this study, we analyzed resected tumor specimens from 131 patients with primary peripheral lung adenocarcinomas with diameters of $30 \mathrm{~mm}$ or less in a period between January 1990 and December 1993. Of the 131 patients, 126 underwent lobectomies, 3 underwent pneumonectomies, and 2 underwent segmental resections combined with systematic hilar and mediastinal node dissection. The CT M/L ratios of tumors were calculated as previously described, ${ }^{5}$ and all the patients were classified into one of two groups: a solid-type tumor group and a faint density-type tumor group. The medical records of all the patients were reviewed for clinical and pathologic characteristics. The length of survival was defined as the period from the day of the operation to the last day of follow-up or the date of death from any cause. Thirty 3- $\mu \mathrm{m}-$ thick sections and two 5- $\mu \mathrm{m}$-thick sections were cut from paraffin blocks of the resected tumor for immunohistochemical staining and microdissection, respectively.

\section{Immunohistochemistry}

Immunohistologic staining was performed by the streptoavidinbiotin method (Histofine SAB-PO Kit; Nichirei, Tokyo, Japan), followed by counterstaining with hematoxylin. For antigen retrieval, sections were autoclaved in $10 \mathrm{mmol} / \mathrm{L}$ citrate buffer $(\mathrm{pH}$ 6.0) before staining. Concentrations of the primary antibodies were optimized by preliminary examinations. Staining without the primary antibody was routinely performed as a negative control. Known immunostaining positive lung adenocarcinoma or squamous cell carcinoma tissue specimens were used as positive controls. The antibodies used in this study were monoclonal p53 antibody (clone DO-7, DAKO, Glostrup, Denmark; diluted 1:50), monoclonal Bcl-2 antibody (clone 124, DAKO, diluted 1:50), monoclonal Ki-67 antibody (clone MIB-1, DAKO, diluted 1:50), monoclonal CD44v6 antibody (clone 2F-10, R\&D systems, Minneapolis, Minn; diluted 1:250), monoclonal VEGF antibody (clone R11, IBL, Fujioka, Gunma, Japan; diluted 1:50), monoclonal CD34 antibody (clone QBEnd 10, DAKO, diluted 1:80), monoclonal MMP-2 antibody (clone 8B4, Santa Cruz Biotechnology, Santa Cruz, Calif; diluted 1:200), monoclonal MMP-9 antibody (clone 2C3, Santa Cruz Biotechnology, diluted 1:250), and monoclonal TIMP-2 antibody (clone 3A4, Santa Cruz Biotechnology, diluted 1:250). All the slides were reviewed by three physicians without any knowledge of clinical outcomes or any other clinicopathologic data: two of them (M.S. and A.S.) received formal cytopathologic training. Microscopic evaluation was performed by counting more than 1000 tumor cells in more than 5 randomly selected high-power fields $(400 \times)$ from different representative parts of the tumor. The Ki-67 labeling index (percentage of nuclear-stained cells) was defined as high when it exceeded the mean value (Figure 1,a). ${ }^{6}$ The $\mathrm{p} 53^{11}$ staining was defined as positive when more than $10 \%$ of the tumor cells showed nuclear staining (Figure 1,b). Bcl-2 (Figure 1, c), ${ }^{6} \mathrm{CD} 44 \mathrm{v} 6$ (Figure 1, $d$ ), ${ }^{7} \mathrm{MMP}-2$ (Figure 1,e), ${ }^{12}$ MMP-9 (Figure $1, f$ ), ${ }^{12}$ and TIMP-2 (Figure 1, $g$ ) ${ }^{12}$ were defined as positive when more than $10 \%$ of the tumor cells showed cytoplasmic staining. For evaluation of VEGF, immunostaining was used to determine the percentage of immunoreactive cells, with the cutoff point for distinguishing specimens with low from high VEGF expression set at $30 \%$ of carcinoma cells (Figure $1, h)$. Microvessel density (MVD), as measured by CD34 immunostaining, was determined by using a modification of the technique described by Weidner and colleagues (Figure 1, $i$ ). ${ }^{13}$ The mean MVD was used as a cutoff point for distinguishing between tumors with low and high MVDs.

\section{Mutation Analysis of K-ras at Codons 12 and 13}

Two hundred or more tumor cells were laser captured on separate Caps by using a laser capture microdissection microscope (Leica AS LMD; Leica Microsystems, Tokyo, Japan), according to the manufacturer's instructions. DNA was extracted with the QIAamp DNA Mini Kit (50; QIAGEN, Tokyo, Japan), according to the protocol provided by the manufacturer. Exon 1 of the K-ras gene was amplified by the nested polymerase chain reaction (PCR) with the first 


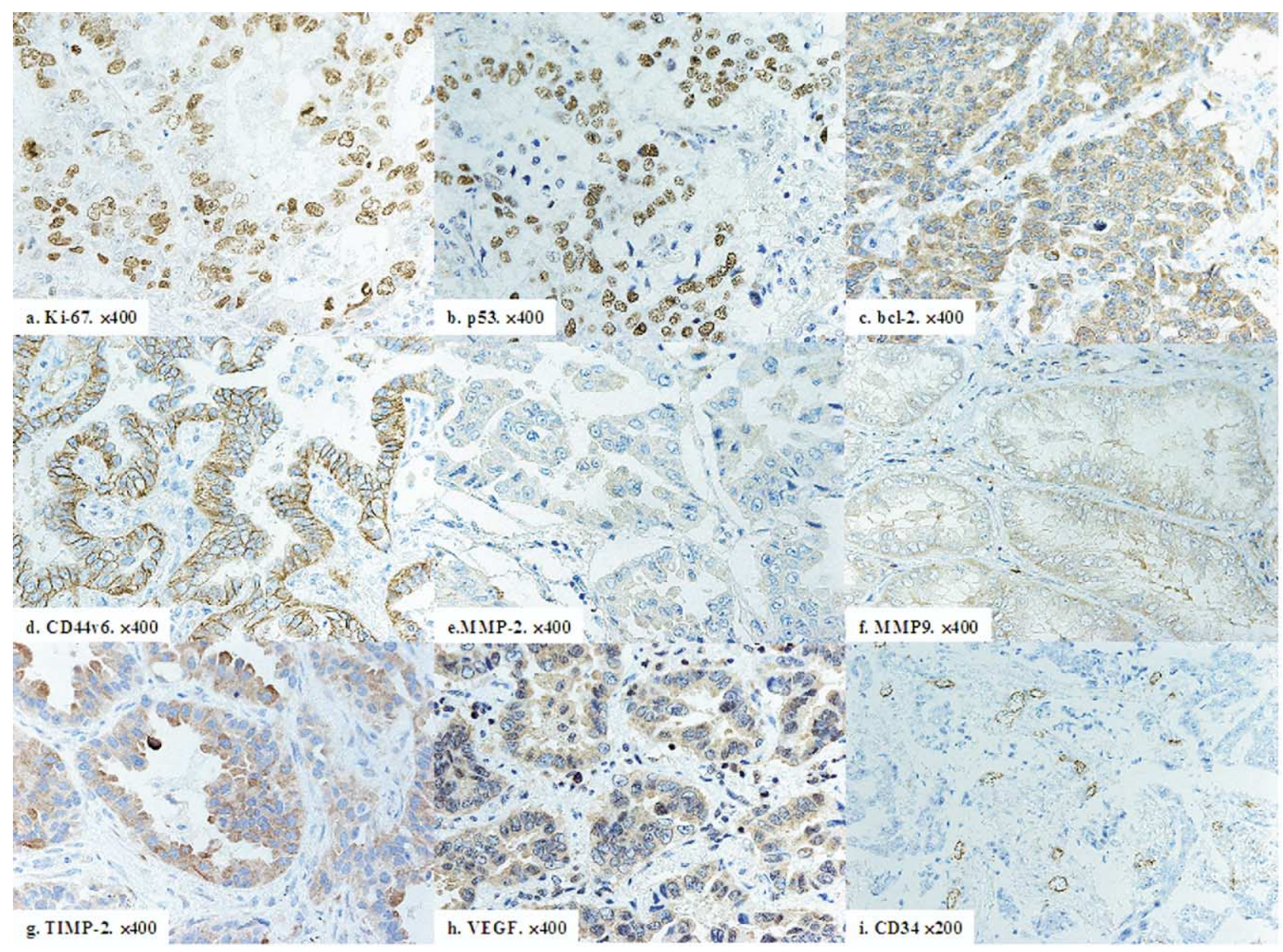

Figure 1. Immunohistochemical staining of serial sections with various antibodies. Nuclear accumulation of Ki-67 (a) and p53 (b) proteins and cytoplasmic accumulation of bcl-2 (c), CD44v6 (d), MMP-2 (e), MMP-9 (f), TIMP-2 (i), and VEGF (h) proteins are shown in neoplastic cells. (Original magnification $400 \times$.) The CD34-stained endothelial cell clusters were considered as a single countable microvessel, and a tumor area with a high microvessel count is shown in i. (Original magnification $200 \times$.)

primer set (5'-GACATGTTCTAATATAGTCACAT-3' and $5^{\prime}$ GTCCTGCACCAGTAATATGC-3') and the nested primer set $\left(5^{\prime}-\right.$ AGGCCTGCTGAAAATGACTG- ${ }^{\prime}$ and $5^{\prime}$-CCTCTATTGTTTGGATCATATTC-3'), which yielded 205-bp and 125-bp DNA fragments, respectively, covering codons 12 and 13. PCR was carried out in a final $25-\mu \mathrm{L}$ reaction mixture containing $4.5 \mathrm{mmol} / \mathrm{L}$ Tris- $\mathrm{HCl}$ (pH 8.8), $67 \mathrm{mmol} / \mathrm{L}\left(\mathrm{NH}_{4}\right)_{2} \mathrm{SO}_{4}, 6.7 \mathrm{mmol} / \mathrm{L} \beta$-mercaptoethanol, 4.5 $\mu \mathrm{mol} / \mathrm{L}$ ethylenediamine tetraacetic acid, $4.5 \mathrm{mmol} / \mathrm{L} \mathrm{MgCl}_{2}, 0.75$ pmol each of deoxyribonucleotide triphosphates, 2.5 pmol of each primer, and 0.25 units of Taq DNA polymerase. ${ }^{14}$ The mixture was heated at $95^{\circ} \mathrm{C}$ for 5 minutes and then subjected to 40 PCR cycles ( $94^{\circ} \mathrm{C}$ for 30 seconds, $55^{\circ} \mathrm{C}$ for 30 seconds, and $72^{\circ} \mathrm{C}$ for 30 seconds). The resulting nested PCR products were run on $4 \%$ agarose gels, the 125-bp fragments were isolated, and the DNAs were purified for sequencing reactions. Nucleotides of both the sense and antisense strands were determined by using the BigDye Terminator Cycle Sequencing Ready FS Reaction Kit (Applied Biosystems,
Foster City, Calif) and ABI PRISM 310 Genetic Analyzer (Applied Biosystems) by means of methods described previously. ${ }^{15}$ This study was approved by the Ethical Committee of Tohoku University School of Medicine and conducted according to the Declaration of Helsinki principles. The appropriate procedure for obtaining informed consent was followed for all the probable individuals participating in the study. Permission for investigations on the old specimens with informed consent that was unavailable during the period of study was obtained from the Ethical Committee of Tohoku University School of Medicine on the basis of a strict evaluation about the essentiality and necessity of the research.

\section{Statistical Analysis}

Survival was calculated by means of the Kaplan-Meier method, and statistical analysis was performed by the log-rank test. The $\chi^{2}$ 
test was used to examine group demographic differences. Binary logistic regression analysis was used to identify predictors of CT $\mathrm{M} / \mathrm{L}$ ratio. The Cox proportional hazards model with a forward stepwise procedure was applied for multivariate analysis. All statistical analyses were performed with version 5.0 of the StatView software package (SAS Institute, Inc, Cary, NC).

\section{Results}

Patient characteristics are summarized in Table 1. There were 53 patients with solid-type tumors and 78 patients with faint density-type tumors. There were no significant differences in sex, age distribution, nodal involvement, or histologic grade between the 2 groups. The 5-year survival of patients with faint density-type images was $81.6 \%$, which was significantly higher than that of patients with solid-type CT images (5-year survival, 63.8\%; $P=.004$; Figure 2, $a$ ).

Positive staining for Ki-67 and p53 protein was detected in the nuclei (Figure 1, $a$ and $b$ ). In all cases the percentage of tumor cells positive for $\mathrm{Ki}-67$ protein ranged from $0.6 \%$ to $78.4 \%$, and the mean $\mathrm{Ki}-67$ labeling index was $18.2 \% \pm$ $16.2 \%$. The expressions of bcl-2, CD44v6, MMP-2, MMP-9, TIMP-2, and VEGF proteins were generally detected in the cytoplasm of tumor cells (Figure $1, c-h$ ). The mean MVD stained by CD34 (Figure 1, $i$ ) for all patients was $59.2 \pm 33.8$. The numbers of patients with high labeling indexes of Ki-67 and high expressions of VEGF, CD34, MMP-2, and MMP-9 in the solid-type group were significantly greater than those in the faint density-type group $(P=.04$ for Ki-67, $P=.03$ for VEGF, $P=.0009$ for CD34, $P=.001$ for MMP-2, and $P=.00001$ for MMP-9; Table 1). The numbers of patients with high levels of CD44v6 or TIMP-2 staining in the faint density-type group were significantly greater than those in the solid-type group ( $P=.02$ for CD44v6 and $P=.01$ for TIMP-2, Table 1$)$. There were no significant differences in the expressions of $\mathrm{p} 53$ and bcl-2 proteins between the 2 groups $(P=.64$ for p53 and $P=.10$ for bcl-2, Table 1$)$. The 5-year survivals of patients with high indexes of Ki-67 or low levels of TIMP-2 staining were poorer than those of patients with low indexes of Ki-67 or high levels of TIMP-2 staining $(P=.026$ for Ki-67 and $P=$ .0005 for TIMP-2; Figure 2, $b$ and $c$ ). The expressions of VEGF, CD34 (MVD), MMP-2, and MMP-9 proteins seem to be unfavorable prognostic factors (Table 1).

DNA extraction, amplification of K-ras by nested PCR, and direct sequencing was successful in 95 cases (43 solid type and 52 faint density type), and K-ras mutations were found in 18 (19\%) tumors, including 17 mutations on codon 12 (9 GGTGly to TGTCys, 4 GGTGly to AGTSer, and 4 GGTGly to GATAsp) and 1 mutation on codon 13 (GGCGly to GACAsp). The frequency of K-ras mutations in the solid-type group was significantly higher than that in the faint density-type group (Table 1). The 5-year survival of patients without a K-ras mutation was 0.78 , which was significantly better than that of those with a K-ras mutation, which was $0.62(P=.04$; Figure $2, d)$.

Binary logistic regression analysis revealed the independent variables of significance in predicting $\mathrm{CT} M / \mathrm{L}$ ratio to be CD34, MMP-9, MMP-2, and TIMP-2 $(P=.0093, P=$ $.0003, P=.0027$, and $P=.01$, respectively). The multivariate analysis showed $\mathrm{N}$ factor, TIMP-2, Ki-67, and tumor size to be significant prognostic factors $(P<.0001, P=$ $.0015, P=.030$, and $P=.048$, respectively; Table 2 ).

\section{Discussion}

In this study we found that patients with solid-type tumors had significantly poorer prognoses than those with faint densitytype tumors (Figure 2). We also observed that a poor prognosis was associated with high Ki-67 expression and K-ras mutation (Figure 2). In multivariate analysis, Ki-67 was proved to be an independent prognostic factor (Table 2). These results were in good agreement with previous reports. ${ }^{6,11,16-20}$ In the solidtype group, the number of patients with high labeling indexes of $\mathrm{Ki}-67$, as well as K-ras mutation, was significantly higher than that in the faint density-type group (Table 1). Positive correlations between K-ras mutation and a high Ki-67 labeling index, a high MVD, a tumor diameter of greater than $20 \mathrm{~mm}$, or low expression of CD44v6 (results not shown) suggest that the K-ras mutation affects biologic behaviors, such as cell proliferation, microvascularization, and cell adhesion, and thus the CT M/L ratio in small peripheral lung adenocarcinoma.

Recently, some researchers have reported that increased levels of VEGF expression and new vessel formation were associated with the poorer survival of patients with nonsmall cell lung cancer. ${ }^{8,9,21-23}$ In this study, the numbers of patients with high expression of VEGF and high MVD in the solid-type group were significantly greater than those in the faint density-type group (Table 1). In binary logistic regression analysis, CD34 (MVD) was an independent variable of significance in predicting $\mathrm{CT} \mathrm{M} / \mathrm{L}$ ratio. All these facts indicated that angiogenesis in the solid-type group was much more vigorous than that in the faint density-type group. The newly formed vessels contribute to the increasing CT M/L ratio, as well as to the patient's poor prognosis. Molecular target therapy against tumor-related vessel formation might be adequate for patients with solid-type CT images.

Several recent reports have confirmed that MMP-2 and MMP-9 might predict the outcome of non-small cell lung cancer.9,24-26 Kumaki and colleagues ${ }^{27}$ and Nawrocki and associates $^{28}$ have also reported that the expressions of MMP-2, MMP-9, and TIMP-2 differed between atypical adenomatous hyperplasia and BAC or between BAC and invasive adenocarcinoma at the mRNA level or as shown by immunostaining study. Therefore, we investigated the expression of these 3 factors and found that the numbers of patients with high levels of expression of MMP-2 and 
TABLE 1. Clinicopathologic characteristics and summary of immunohistochemical studies and K-ras mutations

\begin{tabular}{|c|c|c|c|c|c|c|}
\hline & \multicolumn{2}{|c|}{ CT findings } & \multirow[b]{2}{*}{ Faint density typet } & \multirow[b]{2}{*}{$\chi^{2} P$ value } & \multirow[b]{2}{*}{ 5-y survival } & \multirow{2}{*}{$\begin{array}{c}\text { Log-rank test } \\
P \text { value }\end{array}$} \\
\hline & No. of patients & Solid type* & & & & \\
\hline Sex & & & & .91 & & .40 \\
\hline Male & 61 & 25 & 36 & & 76.4 & \\
\hline Female & 70 & 28 & 42 & & 72.5 & \\
\hline Age (y) & $62.9 \pm 9.7$ & $62.9 \pm 9.6$ & $63.0 \pm 9.8$ & .54 & & .94 \\
\hline Tumor size & & & & .03 & & .01 \\
\hline$\leq 20 \mathrm{~mm}$ & 52 & 15 & 37 & & 83.9 & \\
\hline$>20 \mathrm{~mm}$ & 79 & 38 & 41 & & 68.8 & \\
\hline Nodal involvement & & & & .09 & & $<.00001$ \\
\hline NO & 99 & 36 & 63 & $\mathrm{~N}^{+}$vs $\mathrm{N}^{-}$ & & $\mathrm{N}^{+}$vs $\mathrm{N}^{-}$ \\
\hline N1 & 7 & 2 & 5 & & & \\
\hline N2 & 25 & 15 & 10 & & & \\
\hline Histologic grade & & & & .015 & & .02 \\
\hline Well & 43 & 13 & 30 & Well vs moderate + poor & & Well vs moderate + poor \\
\hline Moderate & 63 & 29 & 34 & & & \\
\hline Poor & 19 & 5 & 14 & & & \\
\hline$p$ stage & & & & .08 & & $<.00001$ \\
\hline $\mathrm{I}$ & 96 & 35 & 61 & Stage I vs stage II-IV & & Stage I vs stage II-IV \\
\hline II & 8 & 2 & 6 & & & \\
\hline III & 26 & 16 & 10 & & & \\
\hline IV & 1 & 1 & 0 & & & \\
\hline p53 & & & & .64 & & .16 \\
\hline Positive & 66 & 28 & 38 & & 67.9 & \\
\hline Negative & 65 & 25 & 40 & & 81.3 & \\
\hline Ki-67 & & & & .04 & & .03 \\
\hline High & 48 & 25 & 23 & & 67.7 & \\
\hline Low & 83 & 28 & 55 & & 79.2 & \\
\hline $\mathrm{Bcl}-2$ & & & & .10 & & .051 \\
\hline Positive & 40 & 12 & 28 & & 82.3 & \\
\hline Negative & 91 & 41 & 50 & & 70.9 & \\
\hline CD44v6 & & & & .02 & & .056 \\
\hline Positive & 80 & 26 & 54 & & 79.4 & \\
\hline Negative & 51 & 27 & 24 & & 66.4 & \\
\hline VEGF & & & & .03 & & .18 \\
\hline Positive & 50 & 26 & 24 & & 66.7 & \\
\hline Negative & 81 & 27 & 54 & & 80.4 & \\
\hline MVD (CD34) & & & & .0009 & & .23 \\
\hline High & 54 & 31 & 23 & & 69.9 & \\
\hline Low & 77 & 22 & 55 & & 77.8 & \\
\hline MMP-2 & & & & .01 & & .82 \\
\hline Positive & 62 & 34 & 28 & & 75.0 & \\
\hline Negative & 69 & 19 & 50 & & 74.2 & \\
\hline MMP-9 & & & & .0001 & & .058 \\
\hline Positive & 93 & 47 & 46 & & 69.0 & \\
\hline Negative & 38 & 6 & 32 & & 87.5 & \\
\hline TIMP-2 & & & & .01 & & .0005 \\
\hline Positive & 90 & 30 & 60 & & 83.3 & \\
\hline Negative & 41 & 23 & 18 & & 55.8 & \\
\hline K-ras mutations & & & & .0003 & & .04 \\
\hline Mutant & 18 & 15 & 3 & & 62.2 & \\
\hline Wild type & 77 & 28 & 49 & & 78.4 & \\
\hline
\end{tabular}

CT, Computed tomography; VEGF, vascular endothelial growth factor; $M V D$, microvessel density; $M M P-2$, matrix metalloproteinase 2; $M M P-9$, matrix metalloproteinase 9; TIMP-2, tissue inhibitor of matrix metalloproteinase 2. *Solid type: area of the tumor in mediastinal window/area of the tumor in lung window of $50 \%$ or greater. $†$ Faint density type: area of the tumor in mediastinal window/area of the tumor in lung window of less than $50 \%$. 

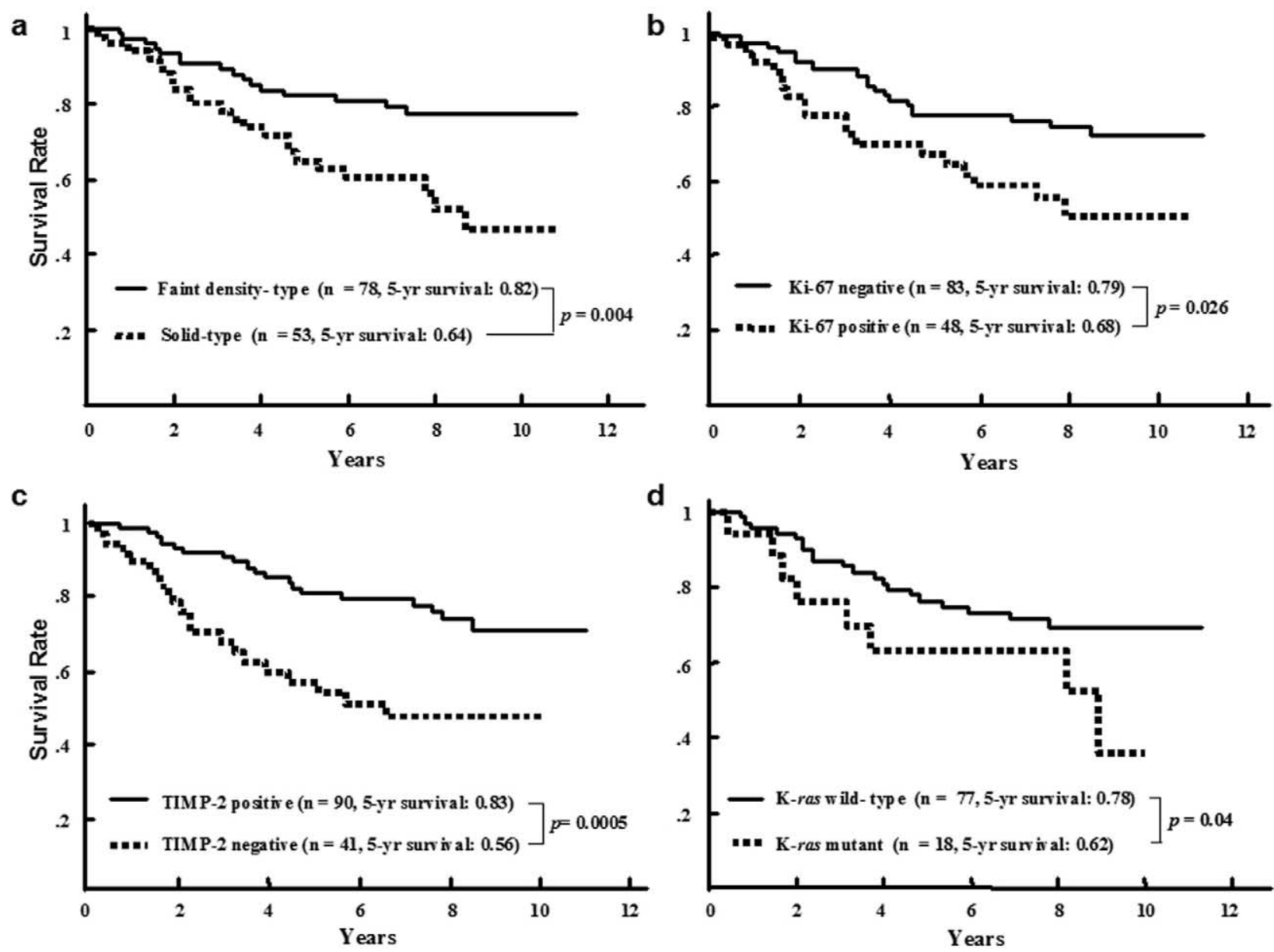

Figure 2. Survivals of patients with faint density-type images, negative Ki-67 immunostaining, or positive TIMP-2 immunostaining were significantly greater than those of patients with solid-type images, positive Ki-67 immunostaining, or negative TIMP-2 immunostaining $(P=.004, P=.026$, and $P=.0005$ in a, b, and $c$, respectively, by using the log-rank test). The 5 -year survival of patients without $K$-ras mutation was 0.78 compared with 0.62 for patients with K-ras mutations ( $P=.04$ in $\mathrm{d})$.

MMP-9 or low levels of expression of TIMP-2 in the solid-type group were significantly greater than those in the faint density-type group (Table 1). Furthermore, MMP-2,

TABLE 2. Multivariate analyses of prognostic factors

\begin{tabular}{lcccc}
\hline \multicolumn{1}{c}{ Variables } & $\begin{array}{c}\text { Estimated } \\
\text { coefficient }\end{array}$ & SE & $\boldsymbol{P}$ value & $\begin{array}{c}\text { Relative risk } \\
(\mathbf{9 5 \%} \text { CI) }\end{array}$ \\
\hline $\begin{array}{l}\text { Nodal involvement } \\
\text { (N0 vs N1 }+2)\end{array}$ & -2.53 & 0.36 & $<.0001$ & $0.08(0.04-0.16)$ \\
TIMP-2 & 1.06 & 0.33 & .0015 & $2.88(1.50-5.54)$ \\
Ki-67 & -0.72 & 0.33 & .030 & $0.49(0.25-0.93)$ \\
$\quad \begin{array}{l}\text { Tumor size (>20 mm } \\
\quad \text { vs } \leq 20 \mathrm{~mm} \text { ) }\end{array}$ & -0.78 & 0.39 & .048 & $0.46(0.21-0.99)$ \\
\end{tabular}

SE, Standard error; $\mathrm{Cl}$, confidence interval; TIMP-2, tissue inhibitor of matrix metalloproteinase 2 .
MMP-9, and TIMP-2 were proved to be the independent variables of significance in predicting $\mathrm{CT} \mathrm{M} / \mathrm{L}$ ratio, and TIMP-2 was proved to be a strong independent prognostic factor of small lung adenocarcinoma both in univariate and multivariate analysis (Tables 1 and 2 and Figure 2,c). All these facts suggested that in addition to angiogenesis, degradation of the extracellular matrix was another important factor that affects the $\mathrm{CT} \mathrm{M} / \mathrm{L}$ ratio, and TIMP-2 might have an important role in the development and extension of lung adenocarcinoma. Further research is necessary to explore the mechanisms of TIMP-2, which affect the $\mathrm{CT} \mathrm{M} / \mathrm{L}$ ratio and the prognosis of small lung adenocarcinoma.

In conclusion, tumors with solid-type or faint densitytype CT images show significant correlations with factors such as immunostaining of Ki-67, CD44v6, VEGF, CD34 (MVD), MMP-2, MMP-9, TIMP-2, and K-ras mutation; 
several factors probably affect the promotion of malignant potential in solid-type tumors. To the best of our knowledge, our study is the first to evaluate the correlation of conventional CT images with these biologic factors and to indicate that the $\mathrm{CT} \mathrm{M} / \mathrm{L}$ ratio might provide some information on a tumor's biologic behaviors and might be a prognostic tool for evaluating patients with small peripheral lung adenocarcinoma in the pretreatment period.

We thank Dr Barbara Lee Smith Pierce (University of Maryland University College) for editorial work in the preparation of this article.

\section{References}

1. Suzuki K, Nagai K, Yoshida J, Nishimura M, Takahashi K, Yokose T, et al. Conventional clinicopathologic prognostic factors in surgically resected non-small cell lung carcinoma. Cancer. 1999;86:1976-84.

2. Noguchi M, Morikawa A, Kawasaki M, Matsuno Y, Yamada T, Hirohashi S, et al. Small adenocarcinoma of the lung-histologic characteristics and prognosis. Cancer. 1995;75:2844-52.

3. Suzuki K, Yokose T, Yoshida J, Nishimura M, Takahashi K, Nagai K, et al. Prognostic significance of the size of central fibrosis in peripheral adenocarcinoma of the lung. Ann Thorac Surg. 2000;69:893-7.

4. Higashiyama M, Kodama K, Yokouchi H, Takami K, Mano M, Kido $\mathrm{S}$, et al. Prognostic value of bronchiolo-alveolar carcinoma component of small lung adenocarcinoma. Ann Thorac Surg. 1999;68:2069-73.

5. Dong B, Sato M, Sagawa M, Endo C, Usuda K, Sakurada A, et al. Computed tomographic image comparison between mediastinal and lung windows provides possible prognostic information in patients with small peripheral lung adenocarcinoma. J Thorac Cardiovasc Surg. 2002;124:1014-20.

6. Ishida H, Irie K, Itoh T, Furukawa T, Tokunaga O. The prognostic significance of p53 and bcl-2 expression in lung adenocarcinoma and its correlation with Ki-67 growth fraction. Cancer. 1997;80:1034-45.

7. Ramasami S, Kerr MK, Chapman DA, King G, Cockburn JS, Jeffrey RR. Expression of CD44v6 but not E-cadherin or $\beta$-catenin influences prognosis in pulmonary adenocarcinoma. J Pathol. 2000;192:427-32.

8. Shibusa T, Shijubo N, Abe S. Tumor angiogenesis and vascular endothelial growth factor expression in stage I lung adenocarcinoma. Clin Cancer Res. 1998;4:1483-7.

9. Kodate M, Kasai T, Hashimoto H, Yasumoto K, Iwata Y, Manabe H. Expression of matrix metalloproteinase (gelatinase) in T1 adenocarcinoma of the lung. Int J Pathol. 1997;47:461-9.

10. Silini ME, Bosi F, Pellegata Gino Volpato SN, Romano A, Tinelli SNC, Ranzani Enrico Solcia NG, et al. K-ras gene mutations: an unfavorable prognostic marker in stage I lung adenocarcinoma. Virchows Arch. 1994;424:367-73.

11. Minami K, Saito Y, Imamura H, Okamura A. Prognostic significance of p53, ki-67, VEGF and Glut-1 in resected stage I adenocarcinoma of the lung. Lung Cancer. 2002;38:51-7.

12. Michael M, Babic B, Khokha R, Tsao M, Ho J, Pintilie M, et al. Expression and prognostic significance of metalloproteinases and their inhibitors in patients with small-cell lung cancer. J Clin Oncol. 1999; 17:1802-8

13. Weidner N, Semple JP, Welch WR, Folkman J. Tumor angiogenesis and metastasis-correlation in invasive breast carcinoma. $N$ Engl J Med. 1991;324:1-8.

14. Kimura M, Abe T, Sunamura M, Matsuno S, Horii A. Detailed deletion mapping on chromosome arm 12 in human pancreatic adenocarcinoma: identification of a 1-cM region of common allelic loss. Genes Chromosomes Cancer. 1996;17:88-93.

15. Sakurada A, Suzuki A, Sato M, Yamakawa H, Orikasa K, Uyeno S, et al. Infrequent genetic alterations of the PTEN/MMAC1 gene in Japanese patients with primary cancers of the breast, lung, pancreas, kidney and ovary. Jpn J Cancer Res. 1997;88:1025-8.

16. Takahashi S, Kamata Y, Tamo W, Koyanagi M, Hatanaka R, Yamada $\mathrm{Y}$, et al. Relationship between postoperative recurrence and expression of cyclin E, p27, and Ki-67 in non-small cell lung cancer without lymph node metastases. Int J Clin Oncol. 2002;7:349-55.

17. Demarchi LMMF, Reis MM, Palomino SAP, Takagaki CFTY, Beyruti R, Saldiva PHN, et al. Prognostic values of stromal proportion and PCNA Ki-67, and p53 proteins in patients with resected adenocarcinoma of the lung. Mod Pathol. 2000;13:511-20.

18. Huncharek M, Muscat J, Geschwind JF. K-ras oncogene mutation as a prognostic marker in non-small cell lung cancer: combined analysis of 881 cases. Carcinogenesis. 1999;20:1507-10.

19. Fukuyama Y, Mitsudomi T, Sugio K, Ishida T, Akazawa K, Sugimachi $\mathrm{K}$. K-ras and p53 mutations are an independent unfavourable prognostic indicator in patients with non-small-cell lung cancer. $\mathrm{Br} \mathrm{J}$ Cancer. 1997;75:1125-30.

20. Cho JY, Kim JH, Lee YH, Chung KY, Kim SK, Gong SJ, et al. Correlation between K-ras gene mutation and prognosis of patients with non-small cell lung carcinoma. Cancer. 1997;79:462-7.

21. Folkman J. Angiogenesis in cancer, vascular, rheumatoid and other disease. Nat Med. 1995;1:27-31.

22. Yano T, Tanikawa S, Fujie T, Masutani M, Horie T. Vascular endothelial growth factor expression and neovascularisation in non-small cell lung cancer. Eur J Cancer. 2000;36:601-9.

23. Inoshima N, Nakanishi Y, Minami T, Izumi M, Takayama K, Yoshino $\mathrm{I}$, et al. The influence of dendritic cell infiltration and vascular endothelial growth factor expression on the prognosis of non-small cell lung cancer. Clin Cancer Res. 2002;8:3480-6.

24. Pinto AC, Carvalho EOP, Antonangelo L, Garippo A, Da Silva AG, Soares F, et al. Morphometric evaluation of tumor matrix metalloproteinase 9 predicts survival after surgical resection of adenocarcinoma of the lung. Clin Cancer Res. 2003;9:3098-104.

25. Thomas P, Khokha R, Shepherd AF, Feld R, Tsao MS. Differential expression of matrix metalloproteinases and their inhibitors in nonsmall cell lung cancer. J Pathol. 2000;190:150-6.

26. Cox G, Joes JL, Andi A, Waller DA, O'Byrne KJ. A biological staging model for operable non-mall cell lung cancer. Thorax. 2001;56:561-6.

27. Kumaki F, Matsui K, Kawai T, Ozeki Y, Yu ZX, Ferrans JV, et al. Expression of matrix metalloproteinases in invasive pulmonary adenocarcinoma with bronchioloalveolar component and atypical adenomatous hyperplasia. Am J Pathol. 2001;159:2125-34.

28. Nawrocki B, Polette M, Marchand V, Monteau M, Gillery P, Tournier $\mathrm{JM}$, et al. Expression of matrix metalloproteinases and their inhibitors in human bronchopulmonary carcinomas: quantitative and morphological analyses. Int J Cancer. 1997;72:556-64. 